\title{
Stimulus compounding in pigeons
}

\author{
CAROLYN K. LONG and JOSEPH D. ALLEN \\ University of Georgia, Athens, Georgia 30602
}

\begin{abstract}
Two pigeons were trained on a three-ply multiple schedule in which reinforcement was available on a VI 1-min schedule for two of the components and extinction was in effect for the third component. $\mathbf{S}_{\mathbf{S}}$ associated with reinforcement were either a tone or a light and the $S \Delta$ associated with the extinction component was the absence of tone and light. After response rates stabilized, testing for summation was conducted with both steady-state and extinction test procedures. Both of these procedures involved 1-min presentations of the compound tone and light. Results indicate that summation did not emerge under the steady-state test conditions but did emerge under extinction test conditions.
\end{abstract}

If two stimuli which separately control responding are combined, responding often increases. Enhanced responding to a compound is generally referred to as response summation. Summation has been found to occur with rats on variable-interval (VI) and fixed-interval (FI) schedules of reinforcement (Wolf, 1963; Weiss, 1964, 1969; Miller \& Ackley, 1970; Meltzer \& Freeman, 1971). The most extensive work in this area has been done with multiple operant schedules employing VI reinforcement schedules which have varied between $30 \mathrm{sec}$ and $120 \mathrm{sec}$ and an extinction component in which responding is not reinforced.

The presence of summation has been typically assessed with one of two testing procedures: an extinction test procedure or a steady-state test procedure. In the extinction test procedure, random presentations of the compound and each of the elements of the compound are presented without any reinforcement for responding until the animal ceases to respond. In a steady-state test procedure, the compound and each of the elements of the compound are presented as nonreinforced test probes which are inserted into the ongoing schedule in some systematic manner. Using such a steady-state test procedure, Meltzer and Freeman (1971) showed that summation could be sustained for 60 days.

Recently, Hamm and Meltzer (1973) attempted to extend the generality of response summation to pigeons in an experiment designed to produce both positive and negative summation. Visual stimuli consisting of forms on the response key and a houselight which was either on or off were correlated either with reinforcement (VI $1 \mathrm{~min}$ ) or extinction. Four birds showed fairly consistent negative summation, but three of the four failed to show positive summation. The one pigeon which did show positive summation did not do so to any great extent. Since it is possible that the procedure these authors used for obtaining negative summation inadvertently precluded positive summation, the present experiment was conducted using a straightforward paradigm which has been successful in producing response summation in rats. It was predicted that the pigeons would demonstrate response summation to the presentation of a compound of tone plus light in both the steady-state and extinction test procedures.

\section{METHOD}

\section{Subjects}

The Ss for this experiment were two male White King pigeons approximately 2 years old, from the Palmetto Pigeon Plant (Sumter, South Carolina), maintained at $75 \%-80 \%$ of their free-feeding body weights.

\section{Apparatus}

The apparatus consisted of a sound-attenuated standard Lehigh Valley operant conditioning chamber for birds, with a modified intelligence panel. The speaker to broadcast the tone, the light, the response key, and the aperture through which reinforcement was delivered were located on the panel.

The tone stimulus was a $2000-\mathrm{Hz}$ tone generated by an Eico audio generator (Model 377). With the white noise of $80 \mathrm{~dB}$ (re: 0.0002 dynes $/ \mathrm{cm}^{2}$ ) and the tone stimulus both on, the sound level was $95 \mathrm{~dB}$, as measured with a sound-level meter (General Radio Co., Type 1551-C). The light stimulus was provided by a $6-\mathrm{V}$ bulb covered with an amber globe. Luminous flux, as measured $5 \mathrm{~cm}$ from the light with an SEI photometer, was 5.85 candles $/ \mathrm{m}^{2}$. The response $\mathrm{key}$, which produced an audible click when depressed, was transilluminated with a green light from a Grason-Stadler multiple stimulus projector. Luminous flux from the response key was .10 candles $/ \mathrm{m}^{2}$. The aperture through which reinforcement was delivered was illuminated by a white light during 3 -sec access to grain. During tests responses were recorded with a serial-parallel digital printer (LVE 1660-9). The entire apparatus was programmed by means of standard electromechanical equipment located in a room adjacent to the experimental chamber.

\section{Procedure}

Both Ss were trained on a three-ply multiple schedule in which random 3-min presentations of tone alone $(T+\bar{L})$ or light alone $(\bar{T}+L)$ were presented for a total of 20 components in which reinforcement was available on separate VI 1-min schedules. Each of these 20 components was preceded and followed by an $\mathrm{S} \Delta$ component in which no reinforcement was made available. The duration of the $S \Delta$ component varied around a mean of $22 \mathrm{sec}$ if no responses occurred. If a response occurred, the VI tape was delayed for $10 \mathrm{sec}$. If another response occurred before the expiration of the 10-sec delay, the delay clock was reset and the 10 -sec delay was reinitiated. Once stimulus control had been established (the response rate in $\mathrm{S} \Delta$ did not exceed $20 \%$ of the average response rate in the $S^{D}$ 


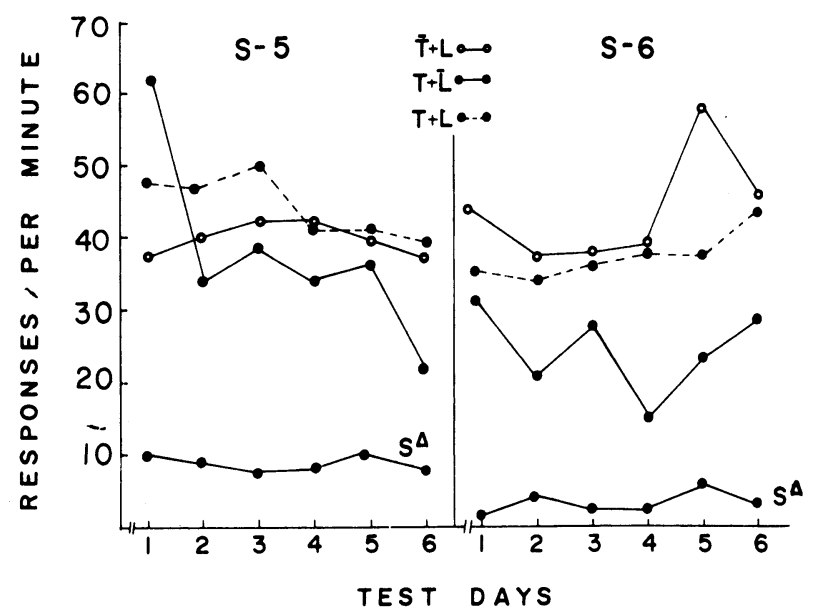

Fig. 1. Mean response rate for each test session for probes of tone alone $(T+\bar{L})$, light alone $(\bar{T}+L)$, or the compound $(T+L)$ for both birds. The $S \Delta$ represents the rate in extinction for the entire session.

components for 5 consecutive days), testing for response summation was conducted.

The steady-state test procedure consisted of adding two test probes of each of the training stimuli $(T+\overline{\mathrm{L}}$ and $\overline{\mathrm{T}}+\mathrm{L})$ and two test probes of the compound $(T+L)$ to the regular schedule in an incomplete counterbalanced order. These six 1-min tests were inserted after every third or fourth component of the regular schedule for 6 consecutive days and each of these sessions was extended to 26 components. No reinforcement was delivered during any of the test probes and each test probe was preceded and followed by an $\mathrm{S} \Delta$ component.

The extinction test procedure, which was conducted about 1 week after completion of the steady-state test, consisted of block randomized 1 -min presentations of $\mathrm{T}+\overline{\mathrm{L}}, \overline{\mathrm{T}}+\mathrm{L}$, and $\mathrm{T}+\mathrm{L}$. Each of these presentations was preceded and followed by an $S \Delta$ period and testing continued until the $S s$ ceased responding (for S-5 60 presentations; for S-6 90 presentations). No reinforcement was delivered during any component of the extinction test.

\section{RESULTS}

Figure 1 shows the mean response rates to test probes of $\overline{\mathrm{T}}+\mathrm{L}, \mathrm{T}+\overline{\mathrm{L}}$, and the compound $\mathrm{T}+\mathrm{L}$ for both $\mathrm{Ss}$ under the steady-state test conditions. Each data point represents the mean of two probes of the test stimuli. The $S \Delta$ rate in the lower part of the figure represents response rate in $S \Delta$ for the entire session. S-5 did show clear summation on Test Days 2 and 3, and a slight summation on Days 5 and 6 . However, this summation was neither as consistent nor as sustained as has been reported with rats. Response rates to $\mathrm{T}+\overline{\mathrm{L}}$ and $\overline{\mathrm{T}}+\mathrm{L}$ were within 8 responses/min of each other except for Days 1 and 6 . On 4 out of the 6 test days response rate to $\overline{\mathrm{T}}+\mathrm{L}$ was higher than response rate to $\mathrm{T}+\overline{\mathrm{L}}$. For $\mathrm{S}-6$, response rate to the compound $\mathrm{T}+\mathrm{L}$ fell between response rates to $\overline{\mathrm{T}}+\mathrm{L}$ and $\mathrm{T}+\overline{\mathrm{L}}$ for all 6 test days. The rates to $\mathrm{T}+\overline{\mathrm{L}}$ and $\overline{\mathrm{T}}+\mathrm{L}$ were never closer than 10 responses/min, which occurred on Test Day 3. For all test days, S-6 showed a higher response rate to $\overline{\mathrm{T}}+\mathrm{L}$ than to $T+\bar{L}$. The rate in $S \Delta$ components of the entire schedule was less than or equal to 10 responses/min for the 6 test days.
Figure 2 shows the results of the extinction test procedure for both Ss in blocks of 4 presentations for S-5 (a total of 60 test presentations) and in blocks of 5 presentations for S-6 (a total of 90 test presentations). Since all presentations of stimuli are test presentations, responses are plotted as cumulative frequencies. As can be seen, responses to the compound $\mathrm{T}+\mathrm{L}$ comprised a larger proportion of total responses than $\operatorname{did} T+\bar{L}$ or $\overline{\mathrm{T}}+\mathrm{L}$ for $\mathrm{S}-5$ and $\mathrm{S}-6$. For $\mathrm{S}-5$ the proportion of responses to the compound $\mathrm{T}+\mathrm{L}$ continued to increase after the third block when responding to $T+\bar{L}$ and $\overline{\mathrm{T}}+\mathrm{L}$ had virtually ceased. For S- 6 the proportion of responses emitted to the compound $\mathrm{T}+\mathrm{L}$ showed only a slight increase after the sixth trial block. Responding to $\mathrm{T}+\overline{\mathrm{L}}$ and $\overline{\mathrm{T}}+\mathrm{L}$ had practically ceased by the fifth trial block. It should also be noted that $\mathrm{S}-5$ emitted a much larger proportion of the total responses to $\bar{T}+L$ than to $\mathrm{T}+\overline{\mathrm{L}}$, but $\mathrm{S}-6$ emitted an approximately equal proportion to both $\overline{\mathrm{T}}+\mathrm{L}$ and $\mathrm{T}+\overline{\mathrm{L}}$. Responses emitted during $\mathrm{S} \triangle$ components were approximately $5 \%$ and $7 \%$ of the total responses for S-5 and S-6, respectively.

\section{DISCUSSION}

It was originally hypothesized that the failure to obtain a clear demonstration of summation in the baseline testing procedure could be a function of the stimulus dimensions chosen. While greater summation has been obtained with stimuli from different modalities with rats (Miller, 1971), it is possible that stimuli from different modalities do not maximize summation with pigeons, particularly since pigeons tend to be more visually oriented than rats. A similar explanation proposed was that the light source provided a punctate signal for the bird, while the tone was a diffuse signal within the chamber.

However, in view of the findings with the extinction test procedure, neither of these explanations was adequate since the stimulus dimensions of the tone and the light were the same for both testing procedures. A more profitable analysis seems to lie in an examination of some of the differences between the two testing procedures.

In the steady-state test procedure, overall reinforcement density during the session typically remains approximately the same as prior to testing. Similarly response rates to $T+\overline{\mathrm{L}}$ and $\overline{\mathrm{T}}+\mathrm{L}$ remain approximately the same for the session components in which reinforcement was available. In the extinction test procedure, overall reinforcement density is

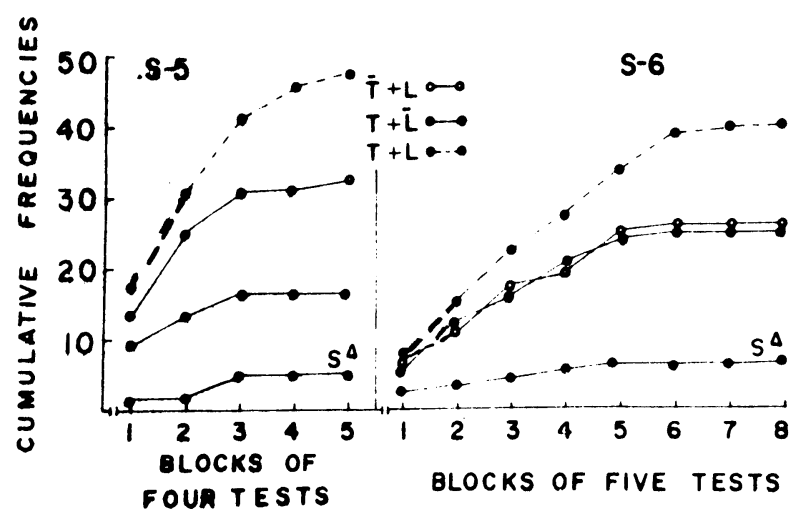

Fig. 2. Cumulative percentage of responses to the test presentations of tone alone $(T+\bar{L})$, light alone $(\bar{T}+L)$, and the compound $(T+L)$ as a function of trial blocks for each bird. 
reduced to zero and response rates to $T+\bar{L}$ and $\bar{T}+L$ systematically decline. Thus, there are differences in both the reinforcement and response rate parameters of the two test procedures. Either of these could account for the present findings. In Hamm and Meltzer's (1973) experiment with pigeons, results indicated a clear demonstration of negative summation but not positive summation. The authors hypothesized that the magnitude of difference in response rates between the two $S D_{S}$ and the $S \Delta$ were not sufficient to produce positive summation. In view of the results of the present experiment, this seems unlikely since the difference in response rates controlled by the two $S^{D_{S}}$ and $S \Delta$ were quite large for both S-5 and S-6.

One possible explanation for the failure to obtain response or positive summation in baseline testing situations is related to the particular reinforcement schedule associated with each component of the multiple schedule. Thus, if the pigeons in Hamm and Meltzer's (1973) experiment and in the present experiment were learning to associate a particular $\mathrm{S}^{\mathbf{D}}$ with a reinforcement density of about 60 reinforcers per hour, then a compound of the $S^{D_{S}}$ would signal a density of approximately 120 reinforcers per hour, if incentive values are additive. But, according to the data presented by Catania and Reynolds (1968), pigeons on VI schedules do not show much increase in response rate above a reinforcement density of approximately 60 reinforcers per hour. Thus, a significant increase in response rate would not be predicted for a compound in which each stimulus was associated with a reinforcement density of 60 reinforcers per hour unless the extinction test procedure was used. Preliminary tests now being conducted indicate that positive summation can be obtained in baseline testing with pigeons on a VI 3-min schedule. While to these authors' knowledge no data has been compiled for rats on VI schedules similar to that of Catania and Reynolds, it has been observed in this lab that rats will increase response rate when reinforcement density is increased above 60 reinforcers per hour. This could account for the differences between data reported for rats and the results of the present experiment with pigeons.

\section{REFERENCES}

Catania, A. C., \& Reynolds, G. S. A quantitative analysis of the responding maintained by interval schedules of reinforcement. Journal of the Experimental A nalysis of Behavior, 1968, 11. 327-383.

Hamm, R. J., \& Meltzer, D. A test for both positive and negative response summation in the pigeon. Bulletin of the Psychonomic Society, 1972, 2, 433-435.

Meltzer, D., \& Freeman, B. J. Maintenance of response summation under conditions of minimum stimulus intensity. Psychonomic Science, 1971, 22, 287-289.

Miller, L. Compounding of discriminative stimuli from the same and different modalities. Journal of the Experimental A nalysis of Behavior, 1971, 16, 337-342.

Miller, L., \& Ackley, R. Summation of responding maintained by fixed-inverval schedules. Journal of the Experimental A naly sis of Behavior, 1970, 13, 199-203.

Weiss, S. J. Summation of response strengths instrumentally conditioned to stimuli in different modalities. Journal of Experimental Psychology, 1964, 68, 151-155.

Weiss, S. J. Attentional processes along a composite stimulus continuum during free-operant summation. Journal of Experimental Psychology, 1969, 82, 22-27

Wolf, M. M. Some effects of combined S'́s. Journal of the Experimental Analysis of Behavior, 1970, 13, 199-203.

(Received for publication May 22, 1974.)

Bulletin of the Psychonomic Society

1974, Vol. 4 (2A), 97-99

\title{
Reinforcement schedule preference of a raccoon (Procyon lotor)*
}

\author{
GLEN D. KING, ROBERT W. SCHAEFFER $\dagger$ \\ Auburn University, Auburn, Alabama 36830 \\ and \\ STEPHEN C. PIERSON \\ University of Minnesota, Minneapolis, Minnesota 55455
}

\begin{abstract}
A raccoon, given a choice to respond for food pellets on either a FI 30-sec schedule or a FR schedule, the response requirement of which was systematically varied, preferred the FR schedule only when the rate of reinforcement on the FR schedule exceeded the rate of reinforcement on the FI schedule by a factor of two. The highly efficient responding of the raccoon on the FI schedule was noted as encouragement for using this species more frequently in operant learning paradigms.
\end{abstract}

A cornucopia of data has been collected concerning the performance of standard laboratory Ss under the contingencies of various reinforcement schedules. However, very little research time has been allocated to investigate the simple preference for reinforcement schedules or the parameters which determine simple schedule preference.

* Supported in part by Public Health Research Grants MG-08775 and MH-12025 from the National Institute of Mental Health, R. W. Schaeffer, principal investigator.

tRequests for reprints should be sent to Glen D. King, Department of Psychology, Auburn University. Appreciation is extended to Robert Bobbitt for competent and reliable assistance in the collection of this data.
The utilization of data from prosaic laboratory Ss such as the albino rat and the college sophomore in psychology has often been criticized. The raccoon, although not new to psychology as an experimental S (e.g., Johnson, 1961; Johnson \& Michels, 1958, 1961; and Hitchcock, Michels, \& Brown, 1963 employed this animal in double alternation and discrimination learning tasks), can readily be employed as a S, provided only that slight modifications are made of existing laboratory manipulanda which must be strengthened against the vigorous barrage of responding of which the raccoon is capable. The present study was undertaken simply to 